\title{
O subimperialismo brasileiro nos sentidos produzidos sobre o brasiguayo no jornalismo paraguaio
}

Maria Liz Benitez Almeida e Ada C. Machado da Silveira

\section{Anexo: Matérias consultadas no Última Hora}

Álvarez, M. R. 03 de 08 de 2014. Del lampíum a internet. http://www.ultimahora.com/dellampium-internet-n817467.html.

Aquino, A. 06 de 02 de 2014. Los proyectos de integración entre los países son siempre políticos. http://www.ultimahora.com/los-proyectos-integracion-los-paises-sonsiempre-politicos-n765124.html.

Aquino, C. 25 de 10 de 2014. Padres de Arlan tienen esperanzas y fe de que liberen pronto a su hijo. http://www.ultimahora.com/padres-arlan-tienen-esperanzas-y-fe-que-liberenpronto-su-hijo-n841605.html.

Aquino, C. M. 21 de 12 de 2014. Ministra afirma que en 5 años el país podría quedar sin bosques. http://www.ultimahora.com/ministra-afirma-que-5-anos-el-pais-podriaquedar-bosques-n857881.html.

Cabral, E. 18 de 05 de 2014. Elección de miss genera polémica en Curuguaty. http://www.ultimahora.com/eleccion-miss-genera-polemica-curuguaty-n795734.html.

Díaz, E. R. 17 de 08 de 2014. Un gerente más político que económico. http://www.ultimahora.com/un-gerente-mas-politico-que-economico-n821335.html.

Duarte, N., e W. Ferreira. 08 de 05 de 2014. Se inicia hoy rueda de negocios en la Expo Santa Rita. http://www.ultimahora.com/se-inicia-hoy-rueda-negocios-la-expo-santarita-n792797.html.

Figueredo, R. 27 de 11 de 2014. Tensión entre brasiguayos y campesinos en Caaguazú. http://www.ultimahora.com/tension-brasiguayos-y-campesinos-caaguazun851112.html.

Giret, R. 16 de 03 de 2014. En todo el país existen tierras del Estado que están siendo usurpadas. http://www.ultimahora.com/en-todo-el-pais-existen-tierras-del-estadoque-estan-siendo-usurpadas-n775350.html.

Giret, R. 27 de 04 de 2014. Clanes familiares se apoderaron de valiosas tierras del Indert. http://www.ultimahora.com/clanes-familiares-se-apoderaron-valiosas-tierras-delindert-n789629.html.

Giret, R. 28 de 04 de 2014. El Indert admite que fue discrecional la entrega de títulos en Santa Lucía. http://www.ultimahora.com/el-indert-admite-que-fue-discrecional-laentrega-titulos-santa-lucia-n789911.html.

Giret, R. 17 de 03 de 2014. Funcionarios del Indert, involucrados en alquiler ilegal de tierras a sojeros. http://www.ultimahora.com/funcionarios-del-indert-involucradosalquiler-ilegal-tierras-sojeros-n775555.html.

Giret, R. 13 de 04 de 2014. Ni las tierras tituladas del Indert en Santa Lucía cumplen la ley agraria. http://www.ultimahora.com/ni-las-tierras-tituladas-del-indert-santa-luciacumplen-la-ley-agraria-n785779.html.

Giret, R. 12 de 03 de 2014. Plan del Gobierno de trasladar a carperos de Nacunday encuentra férrea oposición. http://www.ultimahora.com/plan-del-gobierno-trasladarcarperos-nacunday-encuentra-ferrea-oposicion-n774217.html. 
Giret, R. 29 de 04 de 2014. Titularon tierras a favor de brasileños en Santa Lucía, pese a obstáculo legal. http://www.ultimahora.com/titularon-tierras-favor-brasilenos-santalucia-pese-obstaculo-legal-n790193.html.

Gutiérrez, A. C. 02 de 11 de 2014. La guerra entre dos bandas brasileñas del narcotráfico desangra al Paraguay. http://www.ultimahora.com/la-guerra-dos-bandas-brasilenasdel-narcotrafico-desangra-al-paraguay-n844002.html.

Gutiérrez, A. C. 23 de 08 de 2014. Los padrinos paraguayos del Doctor Horror. http://www.ultimahora.com/los-padrinos-paraguayos-del-doctor-horrorn823108.html.

Medina, E. 14 de 12 de 2014. Aumenta tensión en Santa Lucía. http://www.ultimahora.com/aumenta-tension-santa-lucia-los-carperos-y-los-colonosn855934.html.

Medina, É. 27 de 12 de 2014. Ex carperos impiden a brasiguayos cosechar en la colonia Santa Lucía. http://www.ultimahora.com/ex-carperos-impiden-brasiguayos-cosecharla-colonia-santa-lucia-n859353.html.

Medina, E. 08 de 05 de 2014. Militares trasladan a carperos para la construcción de viviendas provisorias. http://www.ultimahora.com/militares-trasladan-carperos-laconstruccion-viviendas-provisorias-n792807.html.

Medina, E. 20 de 11 de 2014. Ocho horas y media de terror vivió una familia brasiguaya en Santa Rita. http://www.ultimahora.com/ocho-horas-y-media-terror-vivio-una-familiabrasiguaya-santa-rita-n849248.html.

Medina, E. 09 de 04 de 2014. Por colaborar, amenazan a un dirigente. http://www.ultimahora.com/por-colaborar-amenazan-un-dirigente-n784643.html.

Medina, É. 06 de 10 de 2014. Una masiva concurrencia en el Consulado de Brasil en CDE. http://www.ultimahora.com/una-masiva-concurrencia-el-consulado-brasil-cden835905.html.

UH. 17 de 03 de 2014. "No son lugareños, es gente pagada". http://www.ultimahora.com/no-son-lugarenos-es-gente-pagada-n775554.html.

UH. 02 de 04 de 2014. Acusan al Indert de blanqueo a Favero. http://www.ultimahora.com/acusan-al-indert-blanqueo-favero-n782632.html.

UH. 23 de 03 de 2014. Brasil: Bajo crecimiento y hegemonía. http://www.ultimahora.com/brasil-crecimiento-y-hegemonia-n777312.html.

UH. 20 de 11 de 2014. Brasileños son imputados por cuatro delitos tras toma de rehenes. http://www.ultimahora.com/brasilenos-son-imputados-cuatro-delitos-toma-rehenesn849364.html.

UH. 28 de 03 de 2014. Broma sobre. http://www.ultimahora.com/broma-sobren778810.html.

UH. 14 de 10 de 2014. Campesinos piden intervención de colonias de Alto Paraná. http://www.ultimahora.com/campesinos-piden-intervencion-colonias-alto-paranan838440.html.

UH. 09 de 04 de 2014. Cartes toma las riendas para traslado de carperos a Itakyry. http://www.ultimahora.com/cartes-toma-las-riendas-traslado-carperos-itakyryn784638.html.

UH. 25 de 03 de 2014. Colonos cierran ruta y evitan que Indert ingrese a las tierras de Itakyry. http://www.ultimahora.com/colonos-cierran-ruta-y-evitan-que-indert-ingreselas-tierras-itakyry-n777871.html.

UH. 03 de 03 de 2014. Controlan incendio en pastizales de Misiones. http://www.ultimahora.com/controlan-incendio-pastizales-misiones-n771791.html. 
UH. 13 de 05 de 2014. Cooperativistas piden a Cárdenas que se devuelva la paz a Santa Lucía. http://www.ultimahora.com/cooperativistas-piden-cardenas-que-se-devuelvala-paz-santa-lucia-n794209.html.

UH. 03 de 04 de 2014. Destruyen sojal de brasiguayo ubicado al lado de una escuela en Alto Paraná. http://www.ultimahora.com/destruyen-sojal-brasiguayo-ubicado-al-lado-unaescuela-alto-parana-n783206.html.

UH. 11 de 03 de 2014. Detienen a 4 presuntos sicarios de una banda criminal brasileña. http://www.ultimahora.com/detienen-4-presuntos-sicarios-una-banda-criminalbrasilena-n774106.html.

UH. 12 de 12 de 2014. En Santa Lucía, los colonos afirman vivir atemorizados. http://www.ultimahora.com/en-santa-lucia-los-colonos-afirman-vivir-atemorizadosn860029.html.

UH. 22 de 11 de 2014. Entre rehenes y la narcopolítica. http://www.ultimahora.com/entrerehenes-y-la-narcopolitica-n849895.html.

UH. 26 de 12 de 2014. EPP pide a la familia Fick repartir 100 canastas navideñas. http://www.ultimahora.com/epp-pide-la-familia-fick-repartir-100-canastas-navidenasn859141.html.

UH. 13 de 11 de 2014. Ex diputado liberal falleció de un paro cardiaco en hotel capitalino. http://www.ultimahora.com/ex-diputado-liberal-fallecio-un-paro-cardiaco-hotelcapitalino-n847449.html.

UH. 26 de 12 de 2014. Familia Fick repartirá canastas navideñas a pedido del EPP. http://www.ultimahora.com/familia-fick-repartira-canastas-navidenas-pedido-del-eppn859213.html.

UH. 11 de 03 de 2014. Indert interviene hoy sojales ubicados al norte de Alto Paraná. http://www.ultimahora.com/indert-interviene-hoy-sojales-ubicados-al-norte-altoparana-n773987.html.

UH. 25 de 03 de 2014. Indert pedirá prisión para colonos que cerraron acceso en Itakyry. http://www.ultimahora.com/indert-pedira-prision-colonos-que-cerraron-accesoitakyry-n777984.html.

UH. 27 de 03 de 2014. Indert verificará en terreno los lotes titulados de la colonia Santa Lucía. http://www.ultimahora.com/indert-verificara-terreno-los-lotes-titulados-lacolonia-santa-lucia-n778533.html.

UH. 27 de 06 de 2014. Informaron sobre la recuperación de tierras en Itakyry. http://www.ultimahora.com/informaron-la-recuperacion-tierras-itakyry-n807103.html.

UH. 22 de 11 de 2014. Jóvenes brasiguayos abren botella de cerveza a balazos. http://www.ultimahora.com/jovenes-brasiguayos-abren-botella-cerveza-balazosn849923.html.

UH. 27 de 12 de 2014. La Fuerza de Tarea Conjunta baila al son del grupo violento. http://www.ultimahora.com/la-fuerza-tarea-conjunta-baila-al-son-del-grupo-violenton859401.html.

UH. 04 de 04 de 2014. López Perito denuncia intromisión de Brasil en asuntos internos. http://www.ultimahora.com/lopez-perito-denuncia-intromision-brasil-asuntosinternos-n783258.html.

UH. 23 de 02 de 2014. Paraguay extradita a Brasil a narcotraficante del Primer Comando da Capital. http://www.ultimahora.com/paraguay-extradita-brasil-narcotraficante-delprimer-comando-da-capital-n769383.html.

UH. 05 de 08 de 2014. Policía recupera camioneta robada en Argentina. http://www.ultimahora.com/policia-recupera-camioneta-robada-argentinan817765.html. 
UH. 10 de 04 de 2014. Sigue tensión entre el Indert, colonos de Itakyry y carperos de Nacunday. http://www.ultimahora.com/sigue-tension-el-indert-colonos-itakyry-ycarperos-nacunday-n784941.html.

UH. 02 de 04 de 2014. UGP afirma que es lícito sembrar soja y maíz en las colonias. http://www.ultimahora.com/ugp-afirma-que-es-licito-sembrar-soja-y-maiz-lascolonias-n782633.html.

UH. 28 de 03 de 2014. Un blooper de López Perito en la sesión. http://www.ultimahora.com/un-blooper-lopez-perito-la-sesion-n778809.html.

UH. 17 de 03 de 2014. "No son lugareños, es gente pagada". http://www.ultimahora.com/no-son-lugarenos-es-gente-pagada-n775554.html.

UH. 02 de 04 de 2014. Acusan al Indert de blanqueo a Favero. http://www.ultimahora.com/acusan-al-indert-blanqueo-favero-n782632.html.

UH. 23 de 03 de 2014. Brasil: Bajo crecimiento y hegemonía. http://www.ultimahora.com/brasil-crecimiento-y-hegemonia-n777312.html.

UH. 20 de 11 de 2014. Brasileños son imputados por cuatro delitos tras toma de rehenes. http://www.ultimahora.com/brasilenos-son-imputados-cuatro-delitos-toma-rehenesn849364.html.

UH. 28 de 03 de 2014. Broma sobre. http://www.ultimahora.com/broma-sobren778810.html.

UH. 14 de 10 de 2014. Campesinos piden intervención de colonias de Alto Paraná. http://www.ultimahora.com/campesinos-piden-intervencion-colonias-alto-paranan838440.html.

UH. 09 de 04 de 2014. Cartes toma las riendas para traslado de carperos a Itakyry. http://www.ultimahora.com/cartes-toma-las-riendas-traslado-carperos-itakyryn784638.html.

UH. 25 de 03 de 2014. Colonos cierran ruta y evitan que Indert ingrese a las tierras de Itakyry. http://www.ultimahora.com/colonos-cierran-ruta-y-evitan-que-indert-ingreselas-tierras-itakyry-n777871.html.

UH. 03 de 03 de 2014. Controlan incendio en pastizales de Misiones. http://www.ultimahora.com/controlan-incendio-pastizales-misiones-n771791.html.

UH. 13 de 05 de 2014. Cooperativistas piden a Cárdenas que se devuelva la paz a Santa Lucía. http://www.ultimahora.com/cooperativistas-piden-cardenas-que-se-devuelvala-paz-santa-lucia-n794209.html.

UH. 22 de 11 de 2014. Entre rehenes y la narcopolítica. http://www.ultimahora.com/entrerehenes-y-la-narcopolitica-n849895.html.

UH. 13 de 11 de 2014. Ex diputado liberal falleció de un paro cardiaco en hotel capitalino. http://www.ultimahora.com/ex-diputado-liberal-fallecio-un-paro-cardiaco-hotelcapitalino-n847449.html.

Vargas, P. 05 de 05 de 2014. Brasil orienta a sus colonos sobre qué tierras pueden comprar en Paraguay. http://www.ultimahora.com/brasil-orienta-sus-colonos-que-tierraspueden-comprar-paraguay-n791911.html.

Vargas, P. 01 de 05 de 2014. Indert promete a Brasil que respetará derecho de colonos. http://www.ultimahora.com/indert-promete-brasil-que-respetara-derecho-colonosn790884.html. 